\title{
A Comparative Analysis of the Immunological Evolution of Antibody 28B4
}

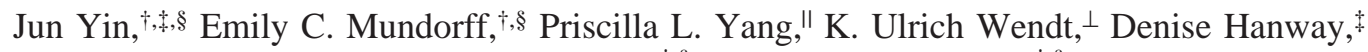 \\ Raymond C. Stevens, ${ }^{*}, \S$ and Peter G. Schultz*,\$, \\ Department of Chemistry and Molecular Biology, The Scripps Research Institute, 10550 North Torrey Pines Road, \\ La Jolla, California 92037, Material Science Division, Lawrence Berkeley National Laboratory, Berkeley, California 94720, \\ Department of Molecular and Experimental Medicine, The Scripps Research Institute, 10550 North Torrey Pines Road, \\ La Jolla, California 92037, and Structural Biology/Chemistry, Aventis Pharma, Building G865, D-65926 Frankfurt, Germany
}

Received March 15, 2001; Revised Manuscript Received May 18, 2001

ABSTRACT: In an effort to gain greater insight into the evolution of the redox active, catalytic antibody 28B4, the germline genes used by the mouse to generate this antibody were cloned and expressed, and the X-ray crystal structures of the unliganded and hapten-bound germline Fab of antibody 28B4 were determined. Comparison with the previously determined structures of the unliganded and hapten-bound affinity-matured Fab [Hsieh-Wilson, L. C., Schultz, P. G., and Stevens, R. C. (1996) Proc. Natl. Acad. Sci. U.S.A. 93, 5363] shows that the germline antibody binds the $p$-nitrophenyl ring of hapten $\mathbf{3}$ in an orientation significantly different from that seen in the affinity-matured antibody, whereas the phosphonate moiety is bound in a similar mode by both antibodies. The affinity-matured antibody 28B 4 has more electrostatic and hydrophobic interactions with hapten $\mathbf{3}$ than the germline antibody and binds the hapten in a lock-and-key fashion. In contrast, significant conformational changes occur in the loops of CDR H3 and CDR L1 upon hapten binding to the germline antibody, consistent with the notion of structural plasticity in the germline antibody-combining site [Wedemayer, G. J., Patten, P. A., Wang, L. H., Schultz, P. G., and Stevens, R. C. (1997) Science 276, 1665]. The structural differences are reflected in the differential binding affinities of the germline Fab $\left(K_{\mathrm{d}}=25 \mu \mathrm{M}\right)$ and 28B4 Fab $\left(K_{\mathrm{d}}=37 \mathrm{nM}\right)$ to hapten 3. Nine replacement mutations were found to accumulate in the affinity-matured antibody 28B4 compared to its germline precursor. The effects of each mutation on the binding affinity of the antibody to hapten $\mathbf{3}$ were characterized in detail in the contexts of both the germline and the affinity-matured antibodies. One of the mutations, Asp $95^{\mathrm{H}} \mathrm{Trp}$, leads to a change in the orientation of the bound hapten, and its presence is a prerequisite for other somatic mutations to enhance the binding affinity of the germline antibody for hapten 3. Thus, the germline antibody of 28B4 acquired functionally important mutations in a stepwise manner, which fits into a multicycle mutation, affinity selection, and clonal expansion model for germline antibody evolution. Two other antibodies, 20-1 and NZA6, with very different antigen specificities were found to be highly homologous to the germline antibody of 28B4, consistent with the notion that certain germline variable-region gene combinations can give rise to polyspecific hapten binding sites [Romesberg, F. E., Spiller, B., Schultz, P. G., and Stevens, R. C. (1998) Science 279, 1929]. The ultimate specificity of the polyspecific germline antibody appears to be defined by CDR H3 variability and subsequent somatic mutation. Insights into the evolution of antibody-combining sites provided by this and other structural studies are discussed.

The evolution of binding affinity in the immune system involves combinatorial and mutational processes, which in many aspects parallel those that occur in the natural evolution of enzymes. Consequently, the characterization of the affinity maturation of catalytic antibodies provides important insights on both the molecular mechanisms of the immune response and the origins of enzymatic catalysis. During the process of affinity maturation, somatic mutations are introduced that increase the binding affinity of the antibody to the antigen

\footnotetext{
* To whom correspondence should be addressed.

These authors contributed equally to this work

Department of Chemistry and Molecular Biology, The Scripps Research Institute.

$\S$ Lawrence Berkeley National Laboratory.

"Department of Molecular and Experimental Medicine, The Scripps Research Institute.

${ }^{\perp}$ Aventis Pharma.
}

(4). Structural studies of affinity-matured catalytic antibodies and their germline precursors have revealed the mechanisms whereby somatic mutations affect binding energy and catalysis. In the case of the catalytic antibody 48G7, which catalyzes ester hydrolysis, the germline antibody undergoes significant conformational changes upon hapten binding (2). In the case of antibody AZ28, which catalyzes an oxy-Cope rearrangement reaction, side chain conformational isomerism is also evident in the germline antibody, and appears to play a dynamic role in catalysis (5). In both cases, somatic mutations lead to a lock-and-key binding mode in the affinity-matured antibody. Thus, it has been proposed that the conformational diversity seen in these germline antibodies significantly enhances the binding potential of the primary antibody repertoire (2).

To further examine the evolution of antibody binding energy and catalysis, we have analyzed the hapten binding 


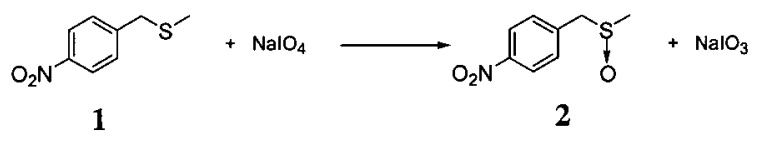

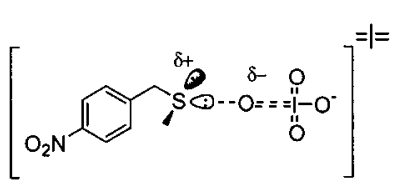

TS-1

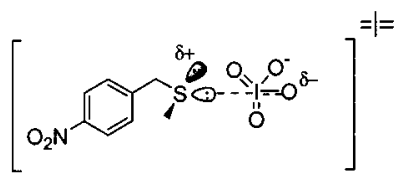

TS-2

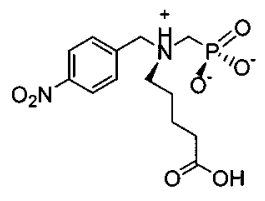

3

FIGURE 1: Periodate-dependent oxygenation of sulfide 1 can occur via two possible transition states (TS-1 and TS-2) to give sulfoxide product 2. Hapten 3 mimics the stereoelectronic features of both transition states and was used to raise antibody $28 \mathrm{~B} 4$.

kinetics and the crystal structures of the catalytic antibody 28B4 and its germline precursor. Antibody 28B4 catalyzes the periodate-dependent oxidation of sulfide 1 to sulfoxide 2 (Figure 1) (6). Oxygen transfer reactions are essential in many biological processes $(7,8)$; enzymes that catalyze these reactions, such as monooxygenase, are dependent on cofactors such as flavin, copper, and heme (9). Antibody catalysis of oxygen transfer reactions can utilize either these natural cofactors or synthetic redox reagents. Hapten $\mathbf{3}$ was designed to mimic the transition state of the oxidation of sulfide $\mathbf{1}$ to sulfoxide 2 using periodate as the cofactor. Of the eight generated antibodies that catalyze the reaction, antibody 28B4 was found to be the most active with a $k_{\text {cat }}$ of $8.2 \mathrm{~s}^{-1}$ and a $k_{\text {cat }} / K_{\mathrm{M}}$ of $1.9 \times 10^{5} \mathrm{M}^{-1} \mathrm{~s}^{-1}(6)$. The X-ray crystal structures of both the unliganded and hapten-bound 28B4 $\mathrm{Fab}^{1}$ were previously determined to 2.2 and $1.9 \AA$, respectively, and revealed a network of hydrogen bonds, electrostatic interactions, and van der Waals interactions that stabilize the transition state for the oxygen transfer reaction (1).

To determine the effects of affinity maturation on binding and catalysis, the germline precursor of antibody $28 \mathrm{~B} 4$ was cloned. A total of nine replacement mutations, two in the light chain and seven in the heavy chain, occurred during the evolution of this antibody. To analyze the effects of these mutations on hapten binding and catalysis, the X-ray crystal structures of the unliganded and hapten-bound germline Fab were determined to 2.1 and $2.8 \AA$ resolution, respectively, and compared with the corresponding structures of the affinity-matured Fab. The binding properties of the 28B4 Fab, the germline Fab, and each single-replacement mutant were also characterized in an effort to determine the functional roles of the somatic mutations.

\footnotetext{
${ }^{1}$ Abbreviations: CDR, complementarity-determining region; EDTA, ethylenediaminetetraacetic acid; Fab, antigen binding fragment; FR, framework region; Hepes, 4-(2-hydroxyethyl)piperazine-1-ethanesulfonic acid; PCR, polymerase chain reaction; PEG, poly(ethylene glycol); $\mathrm{RU}$, resonance unit; Tris, tris(hydroxymethyl)aminomethane; TS, transition state; UTR, untranslated region.
}

\section{MATERIALS AND METHODS}

Reagents and Strains. All chemicals were analytical grade. All solution and media were made with distilled water purified by a Milli-Q plus water purification system (Millipore). Restriction enzymes and DNA-modifying enzymes were purchased from New England Biolabs, Inc. (Beverly, MA). Taq DNA polymerase and plasmid DNA purification kits (Wizard maxiprep and miniprep kits) were purchased from Promega Co. (Madison, WI). The Oligotex mRNA kit, the QIAquick gel extraction kit, and the QIAquick PCR purification kit were purchased from Qiagen Inc. (Valencia, CA). Pfu DNA polymerase and QuickChange site-directed mutagenesis kits were purchased from Stratagene (La Jolla, CA). Ultralink immobilized protein $\mathrm{G}$ was obtained from Pierce Chemical Co. (Rockford, IL). Superdex 200 columns, Mono S HR 5/5 columns, and Mono Q HR 5/5 columns were purchased from Amersham Pharmacia Biotech (Piscataway, NJ). The CM5 sensor chip, the amine coupling kit, and other reagents for surface plasmon resonance experiments were purchased from Biacore Inc. (Piscataway, NJ). Strains for cloning or Fab expression were obtained as competent cells from the following manufacturers: DH5 $\alpha$ (Clontech, Palo Alto, CA), TOP10 (Invitrogen, Carlsbad, CA), and XL1Blue (Stratagene). Samples of plasmid DNA and PCR products were submitted to the DNA sequencing facilities at The Scripps Research Institute or Novartis Institute of Functional Genomics for sequence determination.

Subcloning and Mutagenesis. Vectors for recombinant Fab expression, pBAD-28B4g and pBAD-28B4m, were constructed by subcloning the variable-region genes of the germline precursor antibody and affinity-matured antibody $28 \mathrm{~B} 4$ into the $\mathrm{pBAD}$ vector using restriction sites $\mathrm{SacI}$ and SalI. The germline mutants and 28B4 mutants were generated by site-directed mutagenesis of the pBAD-28B4g and pBAD28B4m templates using a QuickChange site-directed mutagenesis kit. Mixed mutants were constructed by reciprocal swapping of the light chain sequences as SacI-HindIII fragments between plasmids pBAD-28B4g and pBAD$28 \mathrm{~B} 4 \mathrm{~m}$. Successful mutations were screened by restriction mapping and verified in all cases by DNA sequencing.

Fab Expression and Purification. In the pBAD-28B4g and pBAD-28B4m plasmids (and other plasmids generated by site-directed mutagenesis), Fabs were expressed under the regulation of an araBAD promoter as a chimeric construct in which the $\mathrm{V}_{\mathrm{H}}$ and $\mathrm{V}_{\mathrm{L}}$ variable-region genes are fused to the human $\mathrm{C}_{\mathrm{H}} 1$ and $\mathrm{C}_{\kappa}$ constant regions, respectively. $\mathrm{LB}$ medium (2 L) containing $100 \mu \mathrm{g} / \mathrm{mL}$ ampicillin was inoculated with a TOP10 cell overnight culture harboring the plasmid encoding the antibody fragment. Cultures were incubated at $25{ }^{\circ} \mathrm{C}$ until an absorbance at $600 \mathrm{~nm}$ of 0.5 was reached. A filter-sterilized $20 \%$ arabinose solution was then added to a final concentration of $0.2 \%$, and the incubation was continued for an additional $12 \mathrm{~h}$. Periplasmic lysates were prepared by treating the cells with $1 \mathrm{mg} / \mathrm{mL}$ lysozyme in $30 \mathrm{mM}$ Tris- $\mathrm{HCl}$ ( $\mathrm{pH} 8.0), 1 \mathrm{mM}$ EDTA, and $20 \%$ sucrose for $15 \mathrm{~min}$ at room temperature. Purification of the Fab involved three purification steps as described by Ulrich et al. (10): protein $\mathrm{G}$ affinity, Mono S ion exchange, and Superdex 200 size-exclusion chromatography.

Crystallization Conditions and Data Collection. The unliganded germline Fab of 28B4 was crystallized in 100 
$\mathrm{mM}$ ammonium sulfate and $50 \mathrm{mM}$ sodium acetate $(\mathrm{pH}$ 3.9) containing $10 \%$ poly(ethylene glycol) 2000 monomethyl ether. Data were collected at $100 \mathrm{~K}$ using beamline 5.02 of the Advanced Light Source at the Lawrence Berkeley National Laboratory. The reflections were indexed and scaled using HKL2000 (11). A total of 109371 observations were recorded for 51231 unique reflections. The reduced data set was $96.9 \%$ complete between 20 and $2.1 \AA$ (95.2\% between 2.15 and $2.07 \AA$ ) with an $R_{\text {merge }}$ of $5 \%$. The space group was $P 1$ with two molecules in the asymmetric unit. The unit cell dimensions were as follows: $a=36.42 \AA, b=69.65$ $\AA, c=85.31 \AA, \alpha=74.57^{\circ}, \beta=80.18^{\circ}$, and $\gamma=77.55^{\circ}$. For the germline Fab-hapten cocrystals, the crystallization conditions included 26\% PEG 4000, $100 \mathrm{mM}$ Tris (pH 7.5), $800 \mathrm{mM} \mathrm{NaCl}$, and $4 \mathrm{mM}$ hapten 3 . The data were collected at beamline 9-2 at the SSRL and scaled and processed with MOSFLM (12). A total of 47152 observations were recorded with 20056 unique reflections, and the set was $93.6 \%$ complete between 20 and $2.8 \AA$ (91.9\% between 2.8 and $2.9 \AA$ ) with an $R_{\text {merge }}$ of $10 \%$. There were again two molecules in the asymmetric unit, but the space group was $P 2_{1}$. The unit cell dimensions were as follows: $a=54.51$ $\AA, b=126.57 \AA, c=65.57 \AA$, and $\beta=104.61^{\circ}$.

Structure Determination. Both structures were determined by molecular replacement using the program package AMORE (13). Coordinates from the affinity-matured 28B4 were used as a model for the germline Fab-hapten structure, and this structure was used as a model for the unliganded germline Fab structure. Alternate rounds of model building in $\mathrm{O}$ (14) and refinement of the coordinates using CNS version $0.4(15-17)$ were performed until minimization was complete. A total of 278 waters were added to the unliganded germline Fab structure, and no waters were added to the germline $\mathrm{Fab}$-hapten structure. The final models have $R$-factor values of 21.9 and $22.7 \%$ and $R_{\text {free }}$ values of 27.0 and $26.8 \%$ for the germline Fab-hapten complex and the unliganded germline Fab, respectively. Both structures were submitted to the PDB as entries 1FL5 and 1FL6 for the unliganded and hapten-bound Fab structures, respectively. The Fab residue numbering follows Kabat numbering throughout (18).

Determination of the Binding Constants. Hapten $\mathbf{3}$ was synthesized and coupled to BSA following the procedure of Hsieh et al. (6). All kinetic equilibrium binding measurements were performed by surface plasmon resonance using the Biacore 3000 biosensor and research grade CM5 sensor chips (Biacore) essentially as described by Ulrich and Schultz (19). Chips were derivatized with the BSA conjugate of hapten $\mathbf{3}$ using the amine coupling kit, and immobilization levels were adjusted to a Fab binding capacity between 300 and 500 resonance units (RU). Underivatized BSA was coupled on the surface of a neighboring reference flow cell at a similar immobilization level to serve as a blank control. The running buffer was HBSEP [20 mM Hepes (pH 7.4), $150 \mathrm{mM} \mathrm{NaCl}$, and $0.005 \%$ P20] (Biacore). All Fab samples were first dialyzed into the same buffer before injections. After the injection of the Fab fragment, the chip surface was regenerated by a 1 min pulse of $20 \mathrm{mM}$ glycine ( $\mathrm{pH} 2.8$ ). For affinity measurements under equilibrium conditions, various concentrations of Fab were injected at a flow rate of $5 \mu \mathrm{L} / \mathrm{min}$ with a contact time of 20 min to achieve complete equilibration. The equilibrium signal in RU was subtracted from that measured in the reference flow cell, and the slope of a plot of RU/C ( $C$ is the concentration of the Fab fragment) versus RU yielded the inverse of the dissociation constant, $K_{\mathrm{d}} . K_{\mathrm{d}}$ values obtained from multiple independent determinations on different sensor chips varied by less than $10 \%$. Dissociation rates were measured using a series of Fab concentrations varying between $0.1 K_{\mathrm{d}}$ and $10 K_{\mathrm{d}}$. The flow rate was set at $30 \mu \mathrm{L} / \mathrm{min}$, and the "kinject" mode was used for sample injection. The injection of the Fab samples lasted for 2 min followed by a $10 \mathrm{~min}$ dissociation phase before the regeneration of the chip surface. Kinetic data were interpreted with BIAevaluation 3.0 software (Biacore) and successfully fit into a simple 1:1 model of interaction between the Fab and hapten.

\section{RESULTS AND DISCUSSION}

Cloning of the Germline Precursor Antibody to $28 B 4$. Affinity-matured antibody 28B4 was previously cloned and sequenced (10). To identify the candidate germline genes for $28 \mathrm{~B} 4 \mathrm{~V}_{\mathrm{L}}$, its CDR L1 sequence was searched against the Kabat Database of Molecules of Immunological Interest (http://immuno.bme.nwu.edu/) (18). The light chain variable region of antibody 28B4 was found to bear a strong resemblance to the germline gene $\mathrm{V} \kappa 1 \mathrm{C}$ of the $\mathrm{V} \kappa 1$ family, and the coding region of $\mathrm{V} \kappa 1 \mathrm{C}$ was found to differ by only two nucleotides from 28B4 (20). Primers that flank the targeted regions were used to PCR amplify the $\mathrm{V} \kappa 1 \mathrm{C}$ gene from Balb/c genomic DNA. After assembly of the complete consensus sequence for the Balb/c-derived germline $\mathrm{V} \kappa 1 \mathrm{C}$ gene, it was aligned with the $\mathrm{V} \kappa$ gene derived from hybridoma 28B4 genomic DNA and two somatic mutations in the light chain were identified: Ser $25^{\mathrm{L}} \mathrm{Phe}$ in light chain complementarity-determining region 1 (CDR L1) and Pro $40^{\mathrm{L}}$ Ser in the second framework region of the light chain (FR 2) (Figure 2).

A search of the Kabat Database using the 28B4 CDR H2 sequence identified $\mathrm{V} 11$ as the probable germline gene from which $28 \mathrm{~B} 4 \mathrm{~V}_{\mathrm{H}}$ was evolved, and the two differed by 11 nucleotides over the length of the $\mathrm{V}_{\mathrm{H}}$ coding sequence. Sequences of the $5^{\prime}$ UTR, peptide leader, intron, and $\mathrm{V}_{\mathrm{H}}$ coding sequences of the V11 gene from Balb/c mice were previously determined (21). Under the assumption that somatic mutations are unlikely to occur upstream of the $\mathrm{V}_{\mathrm{H}}$ coding sequence, primers were designed to amplify the $5^{\prime}$ UTR of the Balb/c-derived V11 gene. Sequence identity between the consensus 28B4 $\mathrm{V}_{\mathrm{H}}$ intron and that identified from Balb/c genomic DNA confirmed V11 as the germline gene from which the $28 \mathrm{~B} 4 \mathrm{~V}_{\mathrm{H}}$ was evolved. The affinitymatured and germline $\mathrm{V}_{\mathrm{H}}$ coding regions differ at 12 positions. Three mutations are silent, and nine are translated to seven replacement mutations in the heavy chain: $\mathrm{Vall}^{\mathrm{H}_{-}}$ Gly in FR 1, Met $34^{\mathrm{H}} \mathrm{Phe}$, Ser $35^{\mathrm{H}} \mathrm{Asn}$, and Val $37^{\mathrm{H}}$ Ala in CDR $\mathrm{H} 1$, Asn $53^{\mathrm{H}}$ Lys in CDR H2, Ser76 ${ }^{\mathrm{H}}$ Gly in FR 3, and Asp95 ${ }^{\mathrm{H}}-$ Trp in CDR H3 (Figure 2). Asp95 ${ }^{\mathrm{H}}$ is encoded by the last codon of the germline gene V11, and the three-nucleotide mutation at this position from GAT(Asp) to TGG(Trp) is most likely a product of $\mathrm{V}-\mathrm{D}$ joining. Though unlikely, it is also possible that mutation Asp95 ${ }^{\mathrm{H}}$ Trp arose from a threenucleotide deletion-insertion mechanism during affinity maturation (22). Sequence analysis also suggests that the variable regions of antibody 28B 4 are encoded by the following combination of gene segments: $\mathrm{V} \kappa 1 \mathrm{C}$ and $\mathrm{J} \kappa 1$ for 


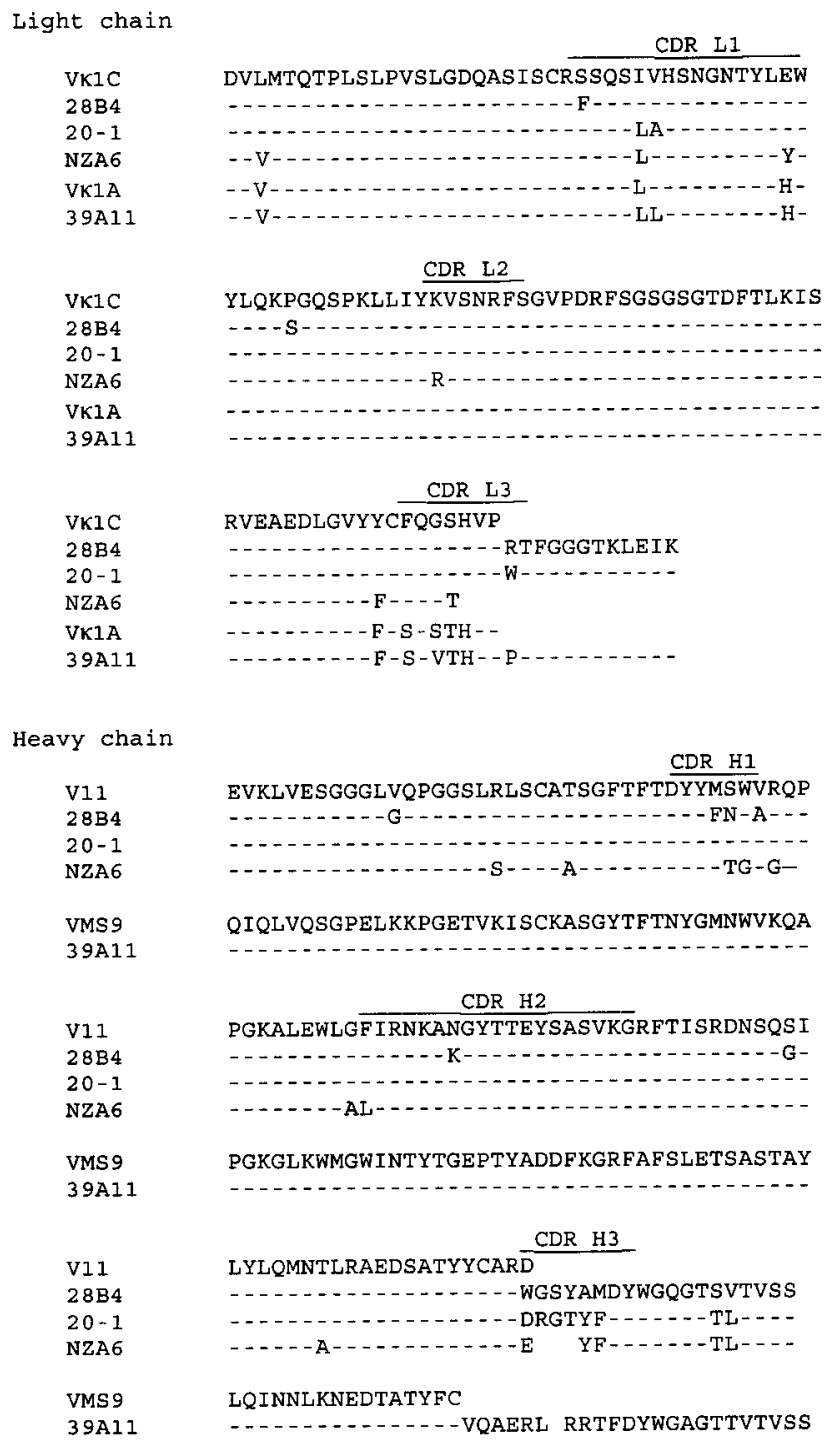

FIGURE 2: Light and heavy chain variable-region sequences of structurally related antibodies 28B4, 20-1, NZA6, and 39A11. Sequences of the germline precursors of the light chain $\mathrm{V}$ gene, $\mathrm{V} \kappa 1 \mathrm{~A}$ and $\mathrm{V} \kappa 1 \mathrm{C}$, and the germline precursors of the heavy chain V gene, V11 and VMS9, are also shown. Dashes represent residues that are identical to that of the corresponding germline $\mathrm{V}$ gene sequence.

the light chain variable region and V11, DFL16.2, and $\mathrm{J}_{\mathrm{H}} 4$ for the heavy chain variable region. The antibody encoded by the unmutated form of this combination is thus assigned to be the germline precursor of antibody $28 \mathrm{~B} 4$.

Structures of the Affinity-Matured $28 B 4$ and Germline Fab-Hapten 3 Complexes. The X-ray crystal structure of hapten 3-bound 28B4 Fab (1) suggests that the antibodycombining site locks the $p$-nitrophenyl substrate and periodate ion into a reactive orientation and stabilizes the transition state for the oxygen transfer reaction through a network of hydrogen bonds, electrostatic interactions, and $\pi$-stacking interactions (Figures 3a and 4a). The oxygen atoms of the phosphonate group of hapten $\mathbf{3}$ form a total of five hydrogen bonds with the active site residues: one with the hydroxyl group of Tyr $33^{\mathrm{H}}$, two with the guanidino group of $\operatorname{Arg} 52^{\mathrm{H}}$, and two with the $\epsilon$-amino group of Lys $53^{\mathrm{H}}$. There is a large hydrophobic cavity consisting of $\operatorname{Tyr} 33^{\mathrm{H}}, \operatorname{Trp} 47^{\mathrm{H}}$, Phe $50^{\mathrm{H}}$, $\mathrm{Trp} 95^{\mathrm{H}}$, and $\mathrm{Phe} 89^{\mathrm{L}}$ that surrounds the $p$-nitrophenyl ring (a)

(b)
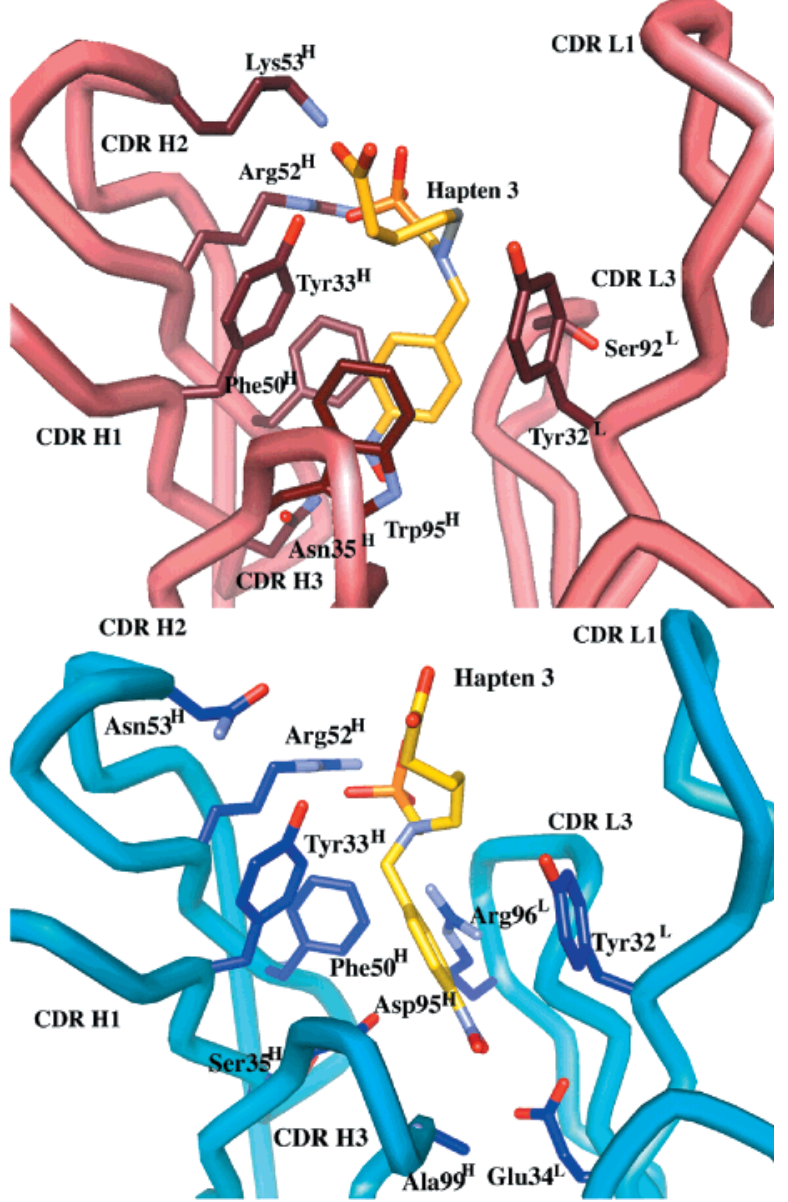

FIGURE 3: View of the active site of the affinity-matured 28B4 Fab-hapten 3 complex (a) and the germline Fab-hapten 3 complex (b). The backbone of the affinity-matured 28B4 Fab is in light brown, and its active site residues are in dark brown. The backbone of the germline Fab is in light blue, and the active site residues are in dark blue. Both haptens are shown in yellow.

of hapten 3. The aromatic rings of $\operatorname{Trp} 95^{\mathrm{H}}$ and $\mathrm{Phe} 50^{\mathrm{H}}$ pack against the $p$-nitrophenyl ring of the hapten, and the carboxamide group of Asn $35^{\mathrm{H}}$ hydrogen bonds to the $p$-nitro group of hapten 3. A comparison of the unliganded and hapten 3-bound 28B4 structures shows only minor differences between the two, consistent with a lock-and-key mechanism in which the antibody-combining site is preorganized for hapten binding.

The crystal structure of the affinity-matured antibody also reveals the site of somatic mutations relative to the binding site of the hapten (Figure 5). Three of the mutations (Ser $35^{\mathrm{H}}-$ Asn, Asn53 $3^{\mathrm{H}} \mathrm{Lys}$, and Asp95 ${ }^{\mathrm{H}} \mathrm{Trp}$ ) occur at the haptenbinding site; four mutations (Ser $25^{\mathrm{L}} \mathrm{Phe}$, Met $34^{\mathrm{H}} \mathrm{Phe}, \mathrm{Va} 137^{\mathrm{H}}-$ Ala, and Ser $76^{\mathrm{H}} \mathrm{Gly}$ ) are one shell removed from the residues that form the hapten-binding pocket. The other two (Pro40 ${ }^{\mathrm{L}}$ Ser and Val1 $2{ }^{\mathrm{H}} \mathrm{Gly}$ ) are close to the constant region of the antibody and far away from the bound hapten.

In the structure of the germline Fab-hapten 3 complex, the hapten is embedded deeply in the antibody-combining site with the phosphonate group and aliphatic linker near the surface, and the $p$-nitrophenyl group at the bottom of the binding pocket. The electron density for hapten $\mathbf{3}$ is shown in Figure 6, and the hapten binding site is shown in 
(a)

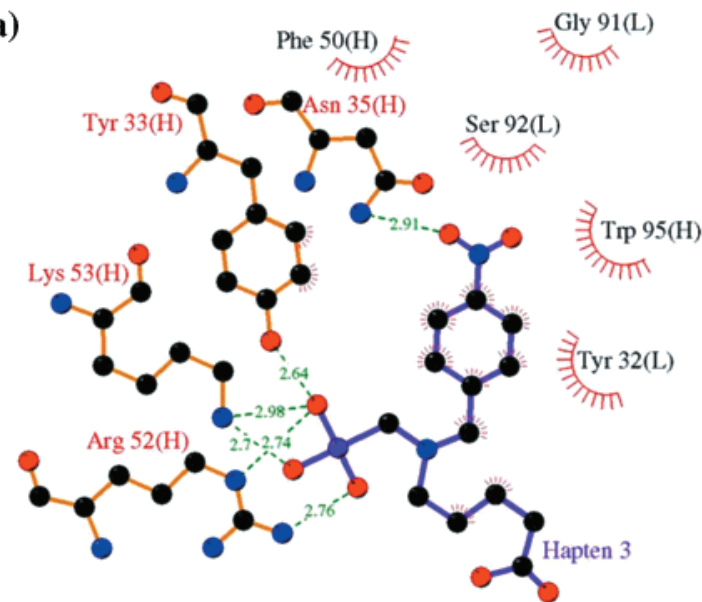

(b)

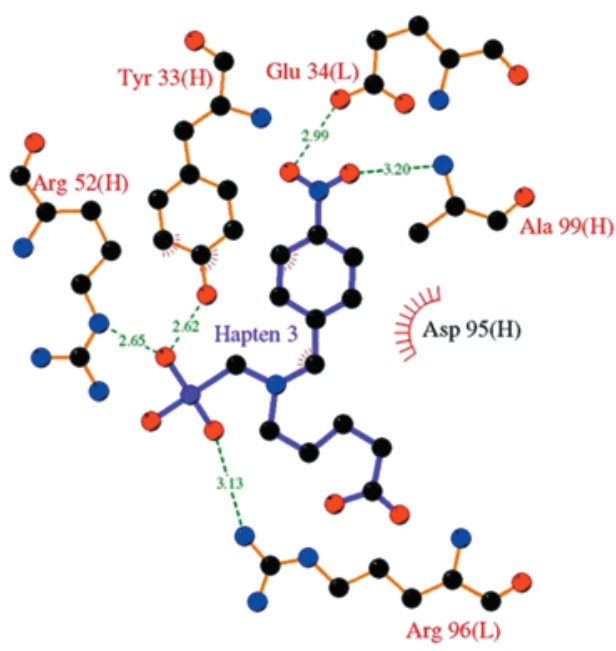

Key

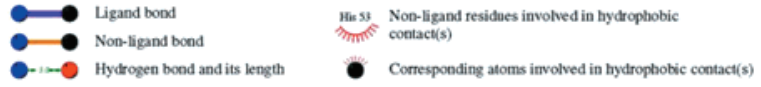

FIGURE 4: Active site residues in the affinity-matured 28B4 Fabhapten complex (a) and in the germline Fab-hapten complex (b). Hapten $\mathbf{3}$ is in purple, and the active site residues are in gold.

Figures $3 \mathrm{~b}$ and $4 \mathrm{~b}$. The strongest interactions between hapten 3 and the germline Fab are with the phosphonate group of the hapten. There are three hydrogen bonds between the active site residues and the oxygen atoms of the phosphonate moiety. The guanidino group of $\operatorname{Arg} 52^{\mathrm{H}}$ and the hydroxyl group of $\mathrm{Tyr} 33^{\mathrm{H}}$ form hydrogen bonds with $\mathrm{O} 14(2.6 \AA)$, and the guanidino group of $\mathrm{Arg} 96^{\mathrm{L}}$ hydrogen bonds with O16 (3.1 A). Although the combining site consists of multiple hydrophobic residues, including Tyr $32^{\mathrm{L}}, \mathrm{Tyr}^{3} 3^{\mathrm{H}}$, and $\mathrm{Phe} 50^{\mathrm{H}}$, only part of the aromatic ring of Tyr $33^{\mathrm{H}}$ is within $4 \AA$ of the $p$-nitrophenyl ring of hapten $\mathbf{3}$. The $p$-nitro group is stabilized by two hydrogen bonds, one between the carboxylate oxygen of Glu34 $4^{\mathrm{L}}$ and $\mathrm{O} 8(3.0 \AA)$ and the second between the backbone amide nitrogen of $\mathrm{Ala} 99^{\mathrm{H}}$ and $\mathrm{O} 9$ (3.2 $⿱$ A). Although there is well-defined electron density for the linker of the hapten, only some minor interactions between the Fab and the linker can be identified. As the structure is at $2.8 \AA$ resolution, no water was added during refinement. It is possible that the linker is stabilized through water hydrogen bonding interactions.

A comparison of the structures of the hapten-bound germline and affinity-matured Fab fragments of antibody

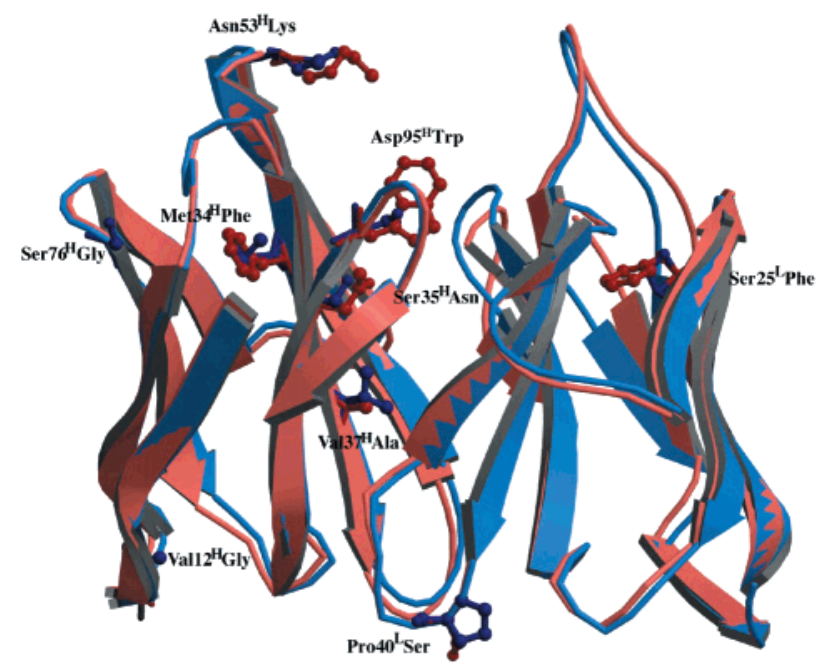

FIGURE 5: Overlay of the germline and affinity-matured 28B4hapten complexes. The germline Fab is shown in blue, and the affinity-matured Fab is shown in pink. The side chains of the somatic mutations are drawn as balls and sticks and are shown in the corresponding colors.

28B4 reveals that hapten 3 is bound in different orientations in the two antibodies (Figure 3). Three mutations (Ser $35^{\mathrm{H}}-$ Asn, Asn53 ${ }^{\mathrm{H}}$ Lys, and Asp95 ${ }^{\mathrm{H}}$ Trp) occur at the antigencombining site during the evolution of the germline antibody and to a large extent are responsible for the new orientation adopted by the bound hapten in the affinity-matured antibody. While the phosphonate group of hapten $\mathbf{3}$ is bound in the same orientation in the two Fabs, the $p$-nitrophenyl ring of hapten 3 in 28B4 Fab is rotated relative to its orientation in the germline Fab, and forms a parallel $\pi$-stacking interaction with the indole ring of $\operatorname{Trp}^{2} 5^{\mathrm{H}}$. The $p$-nitro group of the hapten is rotated away from Glu34 ${ }^{\mathrm{L}}$ and forms a new hydrogen bond with the carboxamide group of $\mathrm{Asn} 35^{\mathrm{H}}$. The Asn $53^{\mathrm{H}}$ Lys somatic mutation introduces two new hydrogen bonds between the $\epsilon$-amino group of $\mathrm{Lys} 53^{\mathrm{H}}$ and the phosphonate moiety of hapten $\mathbf{3}$. Thus, as a result of the active site mutations, hapten $\mathbf{3}$ has gained two additional hydrogen bonds to the phosphonate group and a higher degree of packing complementarity with residues $\operatorname{Trp} 95^{\mathrm{H}}$, Phe $50^{\mathrm{H}}$, Tyr32 ${ }^{\mathrm{L}}$, and $\mathrm{Tyr} 36^{\mathrm{L}}$. This is consistent with the $700-$ fold increase in hapten binding affinity of the affinitymatured antibody relative to the germline antibody.

Structural Consequences of Hapten Binding to the Germline and Affinity-Matured Antibodies. The X-ray crystal structure of the unliganded germline Fab was determined to $2.1 \AA$ resolution. Comparison of the hapten-bound and free germline Fab structures shows that there are significant changes in the loops of CDR H3 and CDR L1 upon hapten binding (Figure 7a). In the hapten-bound structure, residues H95-H99 of CDR H3 are shifted away from hapten 3. In the absence of such a CDR H3 conformational change, the backbone of $\mathrm{Tyr} 98^{\mathrm{H}}$ would sterically clash with the $p$-nitro group of the bound hapten. The backward movement of the backbone of CDR H3 (a maximum of $3.7 \AA$ between the $\mathrm{C} \alpha$ positions of $\mathrm{Tyr} 98^{\mathrm{H}}$ in the two structures) removes this unfavorable steric interaction and at the same time introduces a new hydrogen bond between the backbone amide of Ala99 ${ }^{\mathrm{H}}$ and the $p$-nitro oxygen atom of hapten 3. Asp95 $5^{\mathrm{H}}$ in this loop also makes hydrophobic contacts with the $p$-nitophenyl ring of hapten $\mathbf{3}$. There are also significant movements of 


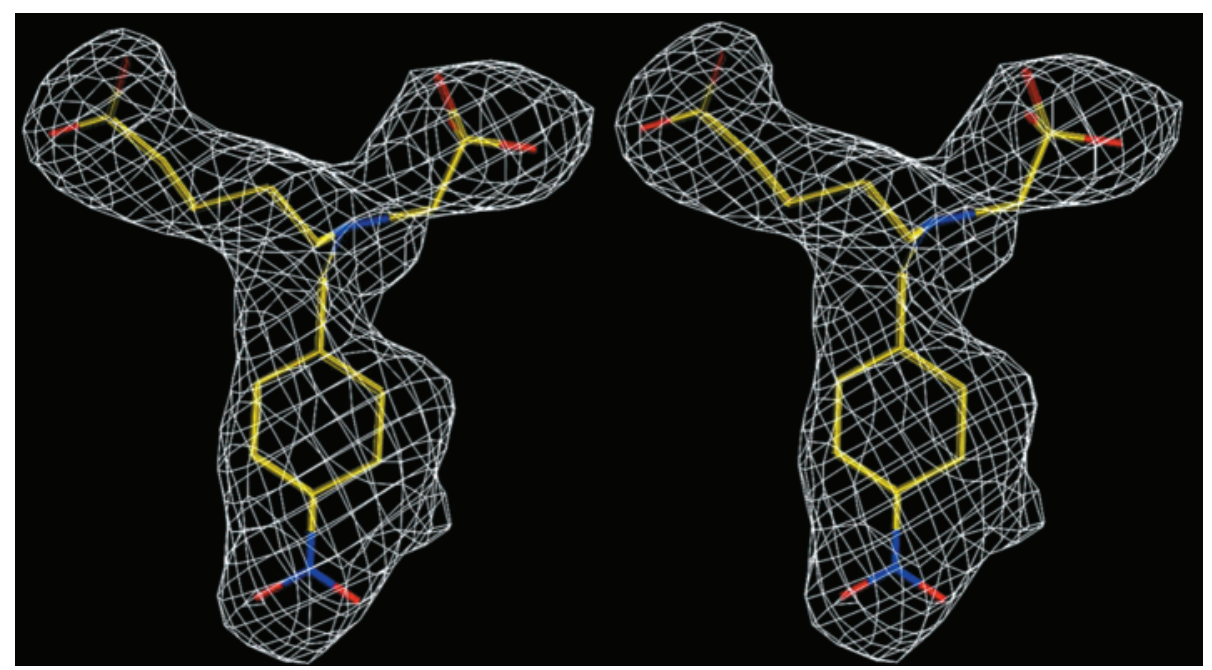

FIGURE 6: $F_{\mathrm{o}}-F_{\mathrm{c}}$ omit electron density map (contoured at 2.0\%) showing the hapten in yellow.

(a)

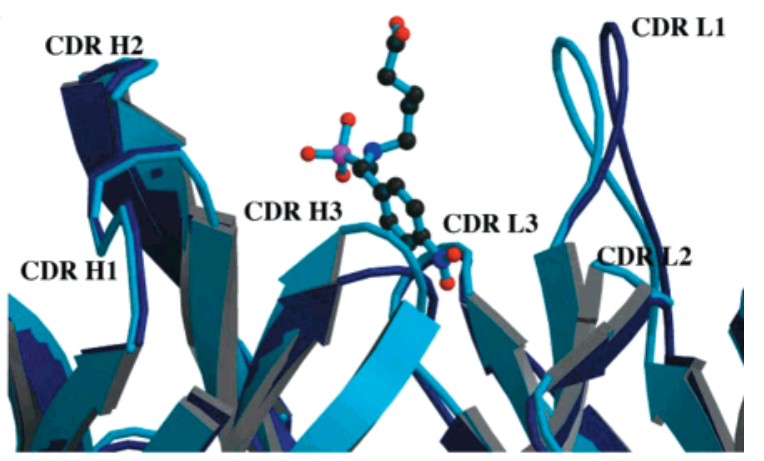

(b)

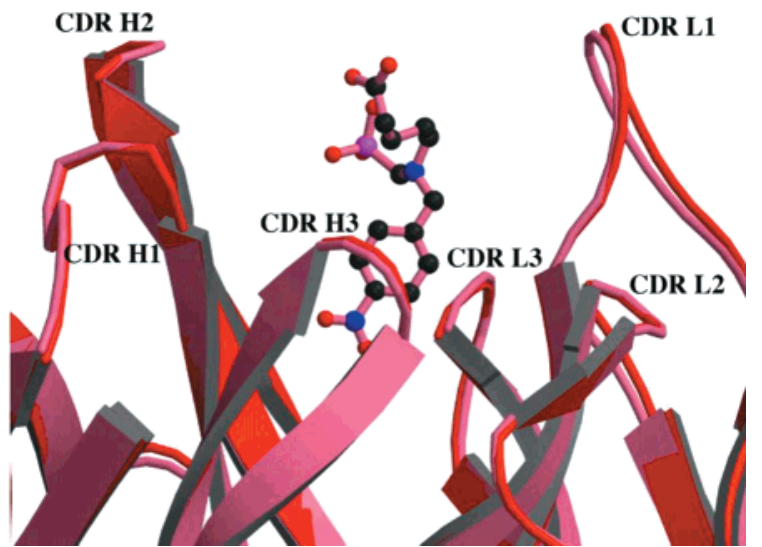

FIGURE 7: (a) Overlay of the unliganded germline Fab (dark blue) and the germline Fab-hapten complex (light blue). The hapten is shown in light blue. (b) Overlay of the unliganded affinity-matured 28B4 Fab (red) and the 28B4 Fab-hapten complex (pink). The hapten is shown in pink.

residues $\mathrm{L} 27 \mathrm{c}-\mathrm{L} 32$ in the CDR L1 loop (a maximum difference of $3.7 \AA$ at the $\mathrm{C} \alpha$ position of $\operatorname{Ser} 27 \mathrm{e}^{\mathrm{L}}$ in the two structures). This results in improved packing interactions, both between the imidazole ring of His $27 \mathrm{~d}^{\mathrm{L}}$ and the aliphatic linker of hapten 3 and between Tyr32 ${ }^{\mathrm{L}}$ and the $p$-nitrophenyl ring of the hapten.

Comparison of the unliganded and hapten-bound affinitymatured 28B4 structures shows that minimal changes occur upon hapten binding (Figure 7b). This is consistent with a lock-and-key mechanism of binding. In contrast, a greater degree of conformational flexibility exists in the germline antibody as demonstrated by the significant loop rearrange- ments and side chain movements that occur upon the binding of hapten 3. These results suggest that a flexible, inducedfit type of binding mode is adopted by the germline antibody of 28B4. It would be interesting to compare the catalytic properties of the germline Fab and the affinity-matured Fab to evaluate the influence of conformational flexibility in the antibody active site on catalysis. At least in one case, the oxy-Cope catalyst AZ28, side chain conformational changes in the germline antibody appear to play a dynamic role in catalysis.

A Comparison of the Affinity Maturation of Catalytic Antibodies. The catalytic antibody 28B4 represents another well-characterized system in which the hapten binding properties of both the germline and the affinity-matured antibody have been investigated at a detailed structural level $(2,5,23,24)$. A common theme arising from structural analyses of the majority of these systems is that the germline antibodies show significant structural changes upon the binding of haptens. In contrast, hapten binds to the affinitymatured antibodies by a lock-and-key mechanism. Thus, it has been proposed that the conformational flexibility of the germline antibodies may provide a mechanism beyond structural diversity for expanding the binding potential of the germline repertoire (2).

A comparison of the hapten-bound and free germline Fab structures of antibodies 28B4, 48G7, and AZ28 shows significant rearrangements of CDR $\mathrm{H} 3$ upon hapten binding in each case. In the germline precursor of antibody 48G7, $\mathrm{Tyr}^{\mathrm{H}}$ and $\mathrm{Try}^{\mathrm{H}} \mathrm{H}^{\mathrm{H}}$ in CDR H3 shift 4.0 and $5.0 \AA$, respectively, in response to hapten association (2). These movements improve the packing interactions between $\mathrm{Tyr} 99^{\mathrm{H}}$, Try $91^{\mathrm{H}}$, and the $p$-nitrophenyl ring of the hapten. In AZ28, CDR H3 is rotated away from the active site in the germline Fab-hapten complex relative to the unliganded structure, and the maximum distance is $4.9 \AA$ between the $\mathrm{C} \alpha$ positions of Phe $99^{\mathrm{H}}(5)$. This movement leads to better $\pi$-stacking interactions between the imidazole ring of $\mathrm{His} 96^{\mathrm{H}}$ and the 2-phenyl group of the bound hapten and better hydrophobic packing between the side chain of $\mathrm{Tyr} 100 \mathrm{a}^{\mathrm{H}}$ and the 2-phenyl group of the hapten. At the same time, this movement appears to allow an increased level of orbital overlap in the transition state of the oxy-Cope reaction catalyzed by AZ28, leading to an enhanced catalytic rate in the germline antibody 
relative to the affinity-matured antibody (5). In the germline precursor of antibody 28B4, residues H95-H99 of CDR H3 are also shifted away from hapten $\mathbf{3}$ upon binding. Again, additional packing interactions between CDR H3 and hapten 3 are introduced as a result of this rearrangement. CDR H3 has also been shown to undergo significant conformational changes upon the binding of antigen in a number of affinitymatured antibodies (25-29). In general, the movement of CDR H3 is not so large $(<2 \AA)$ in the affinity-matured antibodies as in the germline antibodies discussed here. Importantly, in the affinity-matured antibodies 28B4, 48G7, and AZ28, very little conformational change occurs as a result of hapten binding $(1,2,5)$.

CDR H3 is encoded by the gene segment generated through $\mathrm{V}-\mathrm{D}$ recombination and $\mathrm{D}-\mathrm{J}$ recombination. In addition, during recombination events, nucleotides can be randomly deleted from or added to the ends of the gene segments, leading to length variation and even greater diversity. As a result, CDR H3 is found with medium or large surface loops with very different sequences and patterns of interaction (30). Thus, it is not surprising to see that extra flexibility is programmed into CDR $\mathrm{H} 3$ of the germline antibody to expand the structural diversity of the primary repertoire beyond that generated by sequence diversity alone.

The hapten in the germline antibody of AZ28 is bound in a conformation similar to that seen in the affinity-matured antibody-hapten complex. Secondary sphere hydrogen bonding interactions introduced by somatic mutations decrease the flexibility of the CDR H3 loop and fix the bound hapten to a single conformation $(5,24)$. However, in 28B4 and $48 \mathrm{G} 7$, the haptens are bound in different conformations in the germline and the affinity-matured antibodies (2). While the positions of the phosphonate groups of the hapten are essentially the same in both the germline and affinity-matured antibodies of 28B4 and 48G7, the $p$-nitrophenyl groups and the aliphatic linkers are bound in different orientations. These differences in the hapten binding mode result from mutations introduced into the germline antibody during the affinity maturation process that lead to enhanced antibody-hapten complementarity. In antibody 48G7, none of the nine residues introduced by somatic mutation directly contacts the hapten. Affinity maturation appears to play a conformational role in both reorganizing the antibody-hapten binding interactions and limiting the side chain and backbone flexibility of the germline antibody $(2,31)$. In contrast, in the case of antibody 28B4, three somatically mutated residues are in direct contact with the bound hapten, and specific interactions of these residues with the hapten to a large extent account for the altered binding mode and the increased affinity of the affinitymatured antibody relative to the germline antibody (1).

These studies suggest that somatic mutations can increase hapten binding affinity by at least three mechanisms: (i) direct interaction with the bound hapten, (ii) decreasing the structural flexibility of the germline antibody, leading to a preorganized active site for hapten binding in the affinitymatured antibody (2), and (iii) significant reorganization of the antibody-antigen interface in the germline antibody as manifested by different hapten binding geometries in the germline and the affinity-matured antibody. The latter may allow many different weak binding modes to exist in the germline antibody that can be reconfigured and optimized by affinity maturation.
Polyspecificity of the Antigen-Combining Site of the Germline Antibody. A search against the Kabat Database of Molecules of Immunological Interest (18) revealed that two antibodies, 20-1 and NZA6, use $\mathrm{V}_{\mathrm{L}}$ and $\mathrm{V}_{\mathrm{H}}$ chains highly homologous to those of the germline antibody of 28B4 (Figure 2). Antibody 20-1 was raised against the peptide DWEYSVWLSN and was shown to be cross-reactive with DNA (32). Antibody NZA6 was produced by autoimmune mice and displays significant cross-reactivity to self-antigen histone and foreign antigen poly(L-lysine) (33). All three antibodies use light chain and heavy chain variable regions encoded by $\mathrm{V} \kappa 1-\mathrm{J} \kappa 1$ and $\mathrm{V} 11$, respectively, and use different D-J combinations for CDR H3. The DFL16.2$\mathrm{J}_{\mathrm{H}} 4$ joining region gene is used by the germline antibody of $28 \mathrm{~B} 4$, and the DQ52- $\mathrm{J}_{\mathrm{H}} 2$ and DFL16- $\mathrm{J}_{\mathrm{H}} 2$ joining region genes are used by antibodies 20-1 and NZA6, respectively.

The overall sequence homology between the germline antibody of 28B4 and antibody 20-1 is remarkable (Figure 2). In the light chain variable region, antibody 20-1 differs from the germline antibody of 28B4 at only three positions: two in CDR L1 and one in CDR L3. For the heavy chain variable region, the two antibodies have exactly the same sequence up to CDR H3. The sequence of antibody NAZ6 is also homologous with the germline antibody of 28B4 both in the light chain variable region and in the heavy chain up to CDR H3. The fact that all three antibodies share the same combination of $\mathrm{V} \kappa 1-\mathrm{J} \kappa 1$ and $\mathrm{V} 11$ gene segments and bind structurally very different antigens suggests that certain combinations of $\mathrm{V}_{\kappa}-\mathrm{J} \kappa$ and $\mathrm{V}_{\mathrm{H}}$ give rise to CDRs L1-3 and CDRs H1-2 that are responsible for the assembly of a partial antigen-combining site, which is polyspecific in nature. CDR H3, which is encoded by quite different $\mathrm{D}-\mathrm{J}_{\mathrm{H}}$ joining genes in each antibody, is responsible for the ultimate specificity of the fully assembled antibody. This strategy for variable-region gene assembly would benefit the evolution of highly specific antibodies in two ways: (i) by increasing the diversity of the germline antibody binding repertoire since a single combination of $\mathrm{V} \kappa-\mathrm{J} \kappa$ and $\mathrm{V}_{\mathrm{H}}$ can be used to construct combining sites for structurally very different antigens and (ii) by accelerating the immunological evolution process in that a single combination of $\mathrm{V}_{\kappa}-\mathrm{J} \kappa$ and $\mathrm{V}_{\mathrm{H}}$ is polyspecific and can be tested in conjunction with all possible $\mathrm{D}-\mathrm{J}_{\mathrm{H}}$ joining genes for optimal antigen binding specificity and affinity.

While it is clear that CDR H3 plays an important role in determining the specificity of an antibody, it has also been shown that CDR H3 plays a critical role in distinguishing between polyspecific and monospecific antigen-combining sites of the antibody (34). Both monospecific and polyspecific antigen-combining sites can be generated utilizing identical light and heavy chain variable-region sequences in conjunction with a discrete CDR H3. This finding strengthens our observation that certain combinations of $\mathrm{V}_{\kappa}-\mathrm{J} \kappa$ and $\mathrm{V}_{\mathrm{H}}$ give a polyspecific antigen-combining site which is to be tuned by CDR H3 for optimal specificity. And depending on whether there is sufficient specific recognition introduced by $\mathrm{CDR} \mathrm{H} 3$, the final antigen-combining site can be either polyspecific or monospecific in nature.

Antibodies 20-1 and NZA6 are polyspecific and show cross-reactivity with structurally different ligands $(32,33)$. Although yet to be tested, it is very likely that the germline antibody of 28B4 is also polyspecific as suggested by the 
Table 1: Binding Affinities of 28B4 Fab, Germline Fab, and the Mutants for Hapten $\mathbf{3}$

\begin{tabular}{|c|c|c|c|c|c|}
\hline $\mathrm{Fab}$ & $\left(\begin{array}{c}k_{\text {on }} \\
\left(\mathrm{M}^{-1} \mathrm{~s}^{-1}\right)\end{array}\right.$ & $\begin{array}{l}k_{\text {off }} \\
\left(\mathrm{s}^{-1}\right)\end{array}$ & $K_{\mathrm{d}}(\mathrm{M})$ & $\begin{array}{c}\Delta G \\
(\mathrm{kcal} / \mathrm{mol})\end{array}$ & $\begin{array}{c}\Delta \Delta G \\
(\mathrm{kcal} / \mathrm{mol})\end{array}$ \\
\hline germline & 430 & 0.011 & $2.5 \times 10^{-5}$ & -6.3 & $0^{a}$ \\
\hline $\begin{array}{l}28 \mathrm{~B} 4 \\
\text { germline mutants }\end{array}$ & $3.5 \times 10^{5}$ & 0.013 & $3.7 \times 10^{-8}$ & -10.1 & $-3.8^{a}$ \\
\hline Ser25 Phe & 650 & 0.015 & $2.3 \times 10^{-5}$ & -6.3 & $0^{a}$ \\
\hline Pro40 ${ }^{\mathrm{L}} \mathrm{Ser}$ & 480 & 0.013 & $2.7 \times 10^{-5}$ & -6.2 & $0.1^{a}$ \\
\hline Val $12^{\mathrm{H}} \mathrm{Gly}$ & 570 & 0.012 & $2.1 \times 10^{-5}$ & -6.4 & $-0.1^{a}$ \\
\hline Met34 ${ }^{\mathrm{H}} \mathrm{Phe}$ & 480 & 0.011 & $2.3 \times 10^{-5}$ & -6.3 & $0^{a}$ \\
\hline Ser35 $5^{\mathrm{H}}$ Asn & 450 & 0.014 & $3.1 \times 10^{-5}$ & -6.1 & $0.2^{a}$ \\
\hline Val $37^{\mathrm{H}} \mathrm{Ala}$ & 670 & 0.016 & $2.4 \times 10^{-5}$ & -6.3 & $0^{a}$ \\
\hline Asn $53^{\mathrm{H}}$ Lys & 630 & 0.017 & $2.7 \times 10^{-5}$ & -6.2 & $0.1^{a}$ \\
\hline Ser $76^{\mathrm{H}}$ Gly & 860 & 0.019 & $2.2 \times 10^{-5}$ & -6.4 & $-0.1^{a}$ \\
\hline Asp95 $5^{\mathrm{H}}$ Trp & $2.6 \times 10^{4}$ & 0.012 & $4.5 \times 10^{-7}$ & -8.7 & $-2.4^{a}$ \\
\hline Ser $25^{\mathrm{L}} \mathrm{Phe} / \mathrm{Asp} 95^{\mathrm{H}} \mathrm{Trp}$ & $6.0 \times 10^{4}$ & 0.018 & $3.0 \times 10^{-7}$ & -8.9 & $-2.6^{a}$ \\
\hline Ser35 ${ }^{\mathrm{H}}$ Asn/Asp95 $5^{\mathrm{H}}$ Trp & $1.5 \times 10^{5}$ & 0.014 & $9.4 \times 10^{-8}$ & -9.6 & $-3.3^{a}$ \\
\hline $\begin{array}{l}\text { Asn5 } 3^{\mathrm{H}} \text { Lys/Asp } 95^{\mathrm{H}} \text { Trp } \\
\text { 28B4 mutants }\end{array}$ & $1.2 \times 10^{5}$ & 0.013 & $1.1 \times 10^{-7}$ & -9.5 & $-3.2^{a}$ \\
\hline Phe $25^{\mathrm{L}}$ Ser & $1.2 \times 10^{5}$ & 0.012 & $1.0 \times 10^{-7}$ & -9.5 & $0.6^{b}$ \\
\hline Ser $40^{\mathrm{L}}$ Pro & $4.8 \times 10^{5}$ & 0.017 & $3.5 \times 10^{-8}$ & -10.2 & $-0.1^{b}$ \\
\hline Gly $12^{\mathrm{H}}$ Val & $6.1 \times 10^{5}$ & 0.020 & $3.3 \times 10^{-8}$ & -10.2 & $-0.1^{b}$ \\
\hline Phe34 ${ }^{\mathrm{H}}$ Met & $2.5 \times 10^{5}$ & 0.014 & $5.7 \times 10^{-8}$ & -9.8 & $0.3^{b}$ \\
\hline Asn $35^{\mathrm{H}}$ Ser & $2.7 \times 10^{4}$ & 0.010 & $3.7 \times 10^{-7}$ & -8.9 & $1.2^{b}$ \\
\hline Ala37 $7^{\mathrm{H}} \mathrm{Val}$ & $1.6 \times 10^{5}$ & 0.011 & $6.6 \times 10^{-8}$ & -9.8 & $0.3^{b}$ \\
\hline Lys $53^{\mathrm{H}}$ Asn & $4.5 \times 10^{4}$ & 0.010 & $2.2 \times 10^{-7}$ & -9.0 & $1.1^{b}$ \\
\hline Gly $76^{\mathrm{H}} \mathrm{Ser}$ & $3.7 \times 10^{5}$ & 0.020 & $5.5 \times 10^{-8}$ & -9.9 & $0.2^{b}$ \\
\hline $\begin{array}{l}\text { Trp95 } 5^{\mathrm{H}} \text { Asp } \\
\text { mixed mutants }\end{array}$ & 650 & 0.013 & $2.0 \times 10^{-5}$ & -6.4 & $3.7^{b}$ \\
\hline germline $\mathrm{L} / 28 \mathrm{~B} 4 \mathrm{H}$ & $1.3 \times 10^{5}$ & 0.011 & $8.2 \times 10^{-8}$ & -9.7 & $-3.4^{a}$ \\
\hline $28 \mathrm{~B} 4 \mathrm{~L} /$ germline $\mathrm{H}$ & 650 & & $2.3 \times 10^{-5}$ & -6.3 & \\
\hline
\end{tabular}

${ }^{a}$ Relative to germline. ${ }^{b}$ Relative to $28 \mathrm{~B} 4$.

homology of its sequence to those of antibodies 20-1 and NZA6. The germline antibody of 39A11, a catalytic antibody with Diels-Alder activity, was shown to have a polyspecific antigen-combining site on the basis of its ability to bind a panel of structurally diverse antigens (3). The light chain variable region of $39 \mathrm{~A} 11$ comprises $\mathrm{V} \kappa 1 \mathrm{~A}$ and $\mathrm{J} \kappa 1$, while the heavy chain variable region comprises the VMS9, DSP2.2, and $\mathrm{J}_{\mathrm{H}} 4$ gene segments (Figure 2). A comparison to antibodies 28B4, 20-1, and NAZ6 shows that despite their differences in binding specificity, all four antibodies use a light chain variable region encoded by $\mathrm{V} \kappa 1-\mathrm{J} \kappa 1$ recombination, suggesting an intrinsic polyspecificity associated with a $V \kappa 1-J \kappa 1$ light chain. In fact, $V \kappa 1$ is common to a relatively large population of antibodies that binds a large number of antigens, including proteins, DNA, steroids, peptides, and small haptens (20). Thus, the polyspecificity intrinsic to $\mathrm{V} \kappa 1$ may contribute to the ability of the germline repertoire to bind a wide array of chemical structures.

Functional Characterization of the Somatic Mutations. To correlate the structural and functional changes associated with each somatic mutation, the dissociation constants of the Fabhapten complexes $\left(K_{\mathrm{d}}\right)$ and the rate constants of complex formation and dissociation ( $k_{\text {on }}$ and $\left.k_{\text {off }}\right)$ were measured by surface plasmon resonance. The results are shown in Table 1. The 28B4 Fab-hapten 3 complex has a $K_{\mathrm{d}}$ of $37 \mathrm{nM}$ compared to a value of $25 \mu \mathrm{M}$ for the germline Fab-hapten 3 complex, a 700-fold improvement in binding affinity resulting from the affinity maturation process. The higher affinity of the 28B4 Fab for hapten 3 results from a higher on-rate, $3.5 \times 10^{5} \mathrm{M}^{-1} \mathrm{~s}^{-1}$, compared to a value of $430 \mathrm{M}^{-1}$ $\mathrm{s}^{-1}$ for the germline Fab. The off-rates for the two Fabs are virtually the same, $0.013 \mathrm{~s}^{-1}$ for the 28B4 Fab-hapten 3 complex and $0.011 \mathrm{~s}^{-1}$ for the germline $\mathrm{Fab}$-hapten 3 complex. This observation is consistent with the notion that the affinity maturation of antibodies is under both kinetic and thermodynamic control with the on-rate constant playing a critical role in antigen-driven B cell selection (35).

To evaluate the functional role of each somatic mutation, three sets of mutants were created. In the first set, each somatic mutation was introduced individually into the germline antibody. This set of mutants is termed the "germline mutants". For the second set of mutations, each residue in the affinity-matured antibody derived from somatic mutation was switched back to its germline identity. This set of mutants is termed the "28B4 mutants". The third set of mutants is termed the "mixed mutants" in which the light and heavy chains of the germline and the affinity-matured antibodies are cross-combined to evaluate the contribution to binding affinity from the somatic mutations in either the entire light or heavy chain. The binding properties of these mutants are also listed in Table 1. $\Delta G$ s are calculated from the equilibrium dissociation constants $\left(K_{\mathrm{d}}\right) . \Delta \Delta G$ s of the germline mutants are calculated relative to the full germline Fab, and $\Delta \Delta G$ s of the $28 \mathrm{~B} 4$ mutants are calculated relative to the affinity-matured 28B4 Fab.

Mutations at the Hapten-Combining Site $\left(\mathrm{Ser} 35^{H}\right.$ Asn, Asn $53^{\mathrm{H}}$ Lys, and Asp $95^{\mathrm{H}} \mathrm{Trp}$ ). Mutations Ser $35^{\mathrm{H}} \mathrm{Asn}, \mathrm{Asn} 53^{\mathrm{H}}-$ Lys, and Asp95 ${ }^{\mathrm{H}}$ Trp occur at the hapten-binding site of the germline antibody of 28B4. While mutations Ser $35^{\mathrm{H}}$ Asn and Asn $53^{\mathrm{H}}$ Lys are somatic mutations, the Asp $95^{\mathrm{H}} \mathrm{Trp}$ mutation is likely to be introduced by $\mathrm{V}-\mathrm{D}$ joining. All these mutated residues are involved in direct contacts with the hapten in the affinity-matured Fab. The carboxamide group of Asn $35^{\mathrm{H}}$ forms a hydrogen bond to the $p$-nitro group of hapten $\mathbf{3}$; the $\epsilon$-amino group of $\mathrm{Lys} 53^{\mathrm{H}}$ forms two hydrogen bonds with the phosphonate moiety of hapten $\mathbf{3}$, and the indole ring of $\operatorname{Trp} 95^{\mathrm{H}}$ sandwiches the $p$-nitophenyl ring of hapten $\mathbf{3}$ with Phe $50^{\mathrm{H}}$ from the other face (Figures 3 and 4 ). These interactions play important roles in binding the hapten in the orientation adopted by the affinity-matured antibody.

The binding affinities of the germline mutants and the 28B4 mutants at these sites correlate well with the structural differences between the germline and the affinity-matured antibodies. The mutation of $\operatorname{Trp} 95^{\mathrm{H}}$ to Asp in the affinitymatured $\mathrm{Fab}$ reduces the binding constant for binding of the mature $\mathrm{Fab}$ for hapten 3 to $20 \mu \mathrm{M}$, close to the value for the germline Fab $\left(K_{\mathrm{d}}=25 \mu \mathrm{M}\right)$. The Lys $53^{\mathrm{H}}$ Asn and Asn $35^{\mathrm{H}}{ }_{-}$ Ser mutants have $K_{\mathrm{d}} \mathrm{S}$ of 220 and $370 \mathrm{nM}$, respectively, 10fold higher relative to that of the affinity-matured Fab $\left(K_{\mathrm{d}}\right.$ $=37 \mathrm{nM}$ ).

An analysis of the binding affinities of pairwise germline mutations reveals that their effects on hapten binding are coupled and deviate from the simple model in which each somatic mutation enhances the hapten binding affinity by itself and together behaves in an additive fashion. The single Asp95 ${ }^{\mathrm{H}}$ Trp mutation results in a $K_{\mathrm{d}}$ of $450 \mathrm{nM}$, a 55 -fold net gain in binding affinity relative to that of the germline Fab, whereas the $K_{\mathrm{d}} \mathrm{S}$ of the $\mathrm{Ser} 35^{\mathrm{H}}$ Asn and Asn $53{ }^{\mathrm{H}}$ Lys mutants are 31 and $27 \mu \mathrm{M}$, respectively, virtually unchanged from that of the germline Fab. This result suggests that the Asp $95^{\mathrm{H}}$ Trp mutation is largely responsible for switching the hapten from the germline to the affinity-matured binding orientation. The $\pi$-stacking interactions involving $\operatorname{Trp} 95^{\mathrm{H}}$ and Tyr $50^{\mathrm{H}}$, which result from the Asp95 ${ }^{\mathrm{H}}$ Trp mutation, are clearly responsible for the altered binding geometry of the hapten in the affinity-matured antibody. In the germline Fab in which residue $\mathrm{H} 95$ is Asp, the hapten is bound in a 


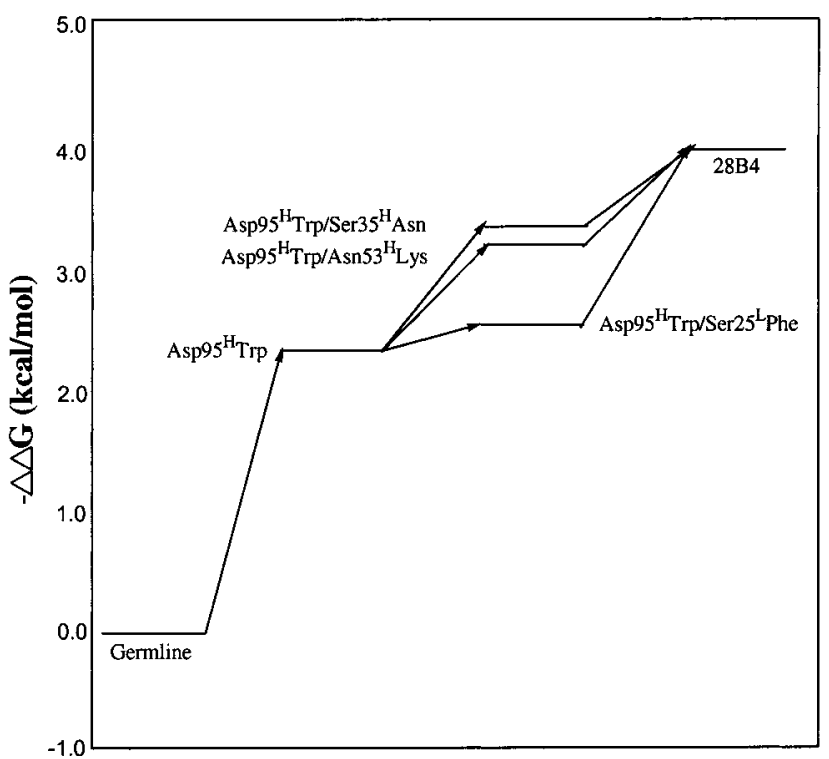

FIGURE 8: Potential energy diagram showing that the stepwise acquisition of somatic mutations is accompanied by a stepwise increase in free binding energy. Arrows pointing to Asp95 ${ }^{\mathrm{H}} \mathrm{Trp} /$ Ser25 ${ }^{\mathrm{L}} \mathrm{Phe}, \mathrm{Asp} 95^{\mathrm{H}} \mathrm{Trp} / \mathrm{Ser} 35^{\mathrm{H}}$ Asn, and Asp95 ${ }^{\mathrm{H}}$ Trp/Asn53 ${ }^{\mathrm{H}}$ Lys are hypothetical but depict the possibility that any of those somatic mutation pairs could be an intermediate step during the affinity maturation of 28B4.

geometry far away from residues $\mathrm{H} 35$ and $\mathrm{H} 53$ such that the somatically mutated residues Asn $35^{\mathrm{H}}$ and Lys $53^{\mathrm{H}}$ are too distant to have any positive effect on hapten binding (Figures $3 \mathrm{~b}$ and $4 \mathrm{~b}$ ). Thus, single somatic mutations at these sites alone do not increase the binding affinity of the germline antibody for the hapten. Indeed, the crystal structure of the germline antibody-hapten 3 complex shows the closest distances between hapten 3 and $\operatorname{Ser} 35^{\mathrm{H}}$ and $\mathrm{Asn} 53^{\mathrm{H}}$ are 9.2 and $7.2 \AA$, respectively. However, the Asp $95^{\mathrm{H}}$ Trp mutation leads to a different orientation of the bound hapten, which allows $A s n 35^{\mathrm{H}}$ and $\mathrm{Lys} 53^{\mathrm{H}}$ to make direct interactions with hapten 3. The double mutants Ser $35^{\mathrm{H}} \mathrm{Asn} / \mathrm{Asp} 95^{\mathrm{H}} \mathrm{Trp}$ and Asn53 ${ }^{\mathrm{H}} \mathrm{Lys} / \mathrm{Asp} 95^{\mathrm{H}} \mathrm{Trp}$ have $K_{\mathrm{d}} \mathrm{s}$ of 94 and $110 \mathrm{nM}$, respectively, corresponding to a roughly 5 -fold gain in binding affinity over that of the single somatic mutant Asp95 $9{ }^{\mathrm{H}}$ Trp $\left(K_{\mathrm{d}}=450 \mathrm{nM}\right)$. Furthermore, when residues $\mathrm{Ser} 5^{\mathrm{H}}$ and Asn $53^{\mathrm{H}}$ in the affinity-matured Fab are mutated to their germline identity (in the context of $\operatorname{Trp}^{2} 5^{\mathrm{H}}$ ), a decrease in hapten binding affinity is seen: the Asn $35^{\mathrm{H}} \mathrm{Ser}$ mutant has a $K_{\mathrm{d}}$ of $370 \mathrm{nM}$, and the Lys53 $3^{\mathrm{H}}$ Asn mutant has a $K_{\mathrm{d}}$ of $220 \mathrm{nM}$, compared to a $K_{\mathrm{d}}$ of $37 \mathrm{nM}$ for the affinity-matured Fab.

These observations suggest that the somatic mutations Ser $35^{\mathrm{H}}$ Asn and Asn $53^{\mathrm{H}}$ Lys must have been selected by the immune system using an intermediate which had already acquired the Asp95 ${ }^{\mathrm{H}} \operatorname{Trp}$ mutation during previous rounds of mutation and selection. Together with the hapten binding data, it can be shown that during the immunological evolution of the germline antibody of 28B4, there is a stepwise acquisition of functional mutations by the germline antibody that concomitantly results in a stepwise increase in hapten binding affinity (Figure 8). This is most likely accomplished through a multicycle mutation, affinity selection, and clonal expansion strategy. A similar context-dependent effect has also been seen with the 48G7 antibody (31); however, this is the first observation that the effects of some somatic mutations are absolutely dependent on other mutations.

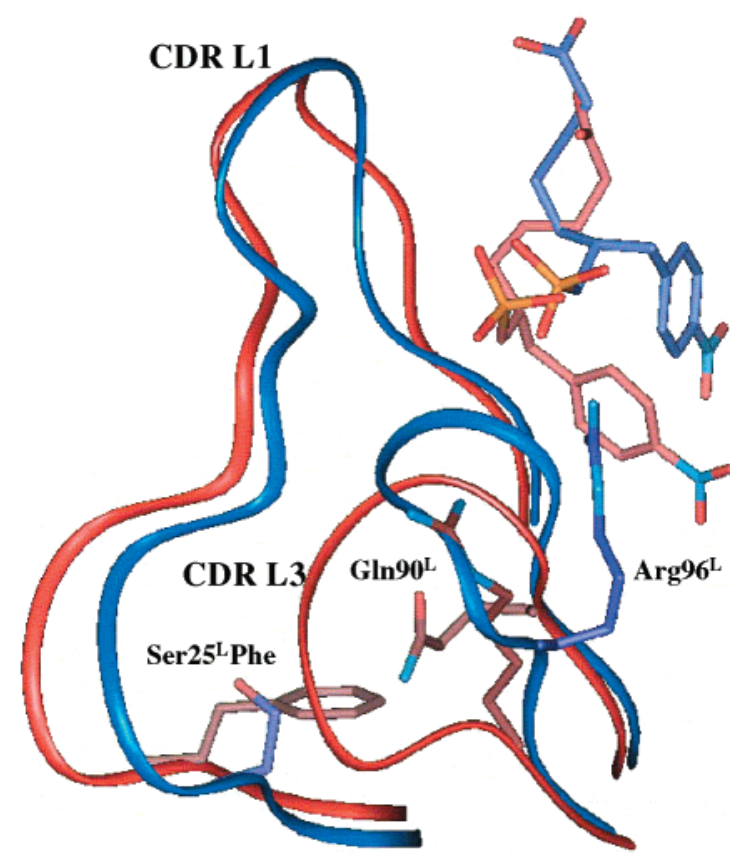

FIGURE 9: Superposition of CDR L1 loops and CDR L3 loops in the germline Fab-hapten 3 complex (blue) and affinity-matured 28B4 Fab-hapten 3 complex (pink). The haptens in the two structures are shown in the corresponding colors. The Ser25 ${ }^{\mathrm{L}} \mathrm{Phe}$ somatic mutation is also shown.

Somatic Mutations Outside the Hapten-Combining Site. The somatic mutations (Ser $25^{\mathrm{L}} \mathrm{Phe}, \mathrm{Met} 34^{\mathrm{H}} \mathrm{Phe}, \mathrm{Val} 37^{\mathrm{H}} \mathrm{Ala}$, and $\left.\operatorname{Ser} 76^{\mathrm{H}} \mathrm{Gly}\right)$ are in the vicinity of the hapten-binding pocket but do not directly contact the hapten. The hapten binding data show that the mutation of Phe $25^{\mathrm{L}} \mathrm{Ser}$ in the affinity-matured antibody increases the $K_{\mathrm{d}} 3$-fold. In the crystal structure of the 28B4-hapten 3 complex, the phenyl ring of Phe $25^{\mathrm{L}}$ packs against the side chain of $\mathrm{Gln} 90^{\mathrm{L}}$ which is located 3.5 $\mathrm{A}$ away on CDR L3. Superimposition of the structures of the germline and the affinity-matured 28B4 Fab-hapten 3 complexes illustrates that CDR L3 undergoes a significant change in the loop conformation during affinity maturation (Figure 9). The differences between CDR L3 in the two structures occur between L89 and L99 with a maximum change of $6.5 \AA$ in the position of the guanidino group of $A \operatorname{Arg}^{2} 6^{\mathrm{L}}$. In the germline antibody, $\operatorname{Arg} 96^{\mathrm{L}}$ extends into the active site and the guanidino group hydrogen bonds to the phosphonate moiety of hapten 3 (Figure $4 b$ ). In the affinity-matured antibody, $\operatorname{Arg} 96^{\mathrm{L}}$ together with residues L89-L99 is shifted backward to accommodate the $p$ nitrophenyl ring of hapten $\mathbf{3}$ which binds in an orientation different from that of the germline antibody. Apparently, a Ser $25^{\mathrm{L}} \mathrm{Phe}$ somatic mutation introduces new packing interactions between Phe $25^{\mathrm{L}}$ and $\mathrm{Gln} 90^{\mathrm{L}}$ that help to stabilize the conformation of the CDR L3 loop in the affinity-matured antibody.

The mutation of Ser25 $5^{\mathrm{L}}$ to Phe in the germline Fab does not increase the hapten binding affinity, presumably due to the fact that the bound hapten still adopts a "germline orientation" in the absence of the Asp95 ${ }^{\mathrm{H}} \operatorname{Trp}$ mutation. However, the double mutant Ser $25^{\mathrm{L}} \mathrm{Phe} / \mathrm{Asp} 95^{\mathrm{H}} \mathrm{Trp}$ has a $K_{\mathrm{d}}$ of $300 \mathrm{nM}$ and does increase the binding affinity over that of the single Asp95 ${ }^{\mathrm{H}} \operatorname{Trp}$ mutant $\left(K_{\mathrm{d}}=450 \mathrm{nM}\right)$ (Figure 8).

Somatic mutations Met $34^{\mathrm{H}} \mathrm{Phe}$ and $\mathrm{Val} 37^{\mathrm{H}} \mathrm{Ala}$ are located on CDR H1 in proximity to the structurally important Ser $35^{\mathrm{H}_{-}}$ 
Asn somatic mutation. Mutation to the germline residues at these sites results in a moderate decrease in hapten binding affinity of the affinity-matured Fab: $K_{\mathrm{d}} \mathrm{s}$ of 57 and $66 \mathrm{nM}$ for the Phe $34^{\mathrm{H}}$ Met and Ala $37^{\mathrm{H}}$ Val mutants, respectively, compared to a $K_{\mathrm{d}}$ of $37 \mathrm{nM}$ for the affinity-matured Fab. These residues may play a role in positioning CDR H1 and Asn $35^{\mathrm{H}}$ for improved packing interactions with hapten 3.

The Ser $76^{\mathrm{H}}$ Gly somatic mutation removes packing interactions between the serine side chain and $\mathrm{Phe} 29^{\mathrm{H}}$, which is involved in a $\beta$-turn proceeding CDR H1. The " $28 \mathrm{~B} 4 \mathrm{mu}$ tant" Gly $76^{\mathrm{H}}$ Ser shows a small increase in $K_{\mathrm{d}}$, suggesting that this somatic mutation may play a role in modulating the turn conformation and affecting CDR H1 interactions with hapten 3. The two other somatic mutations, Pro $40^{\mathrm{L}} \mathrm{Ser}$ and Val12 ${ }^{\mathrm{H}} \mathrm{Gly}$, are located at the peripheries of the antibody and far from the bound hapten. The $K_{\mathrm{d}} \mathrm{s}$ of the 28B4 mutants at those sites are the same as those of the affinity-matured Fab.

\section{CONCLUSION}

The immune system is able to generate high-affinity receptors for virtually any chemical structure through its ability to generate a large library of antibodies and select members of the library based on the affinity of the antibody with antigen. Diversity of the antibody library results from the combinatorial association of the $\mathrm{V}, \mathrm{D}$, and $\mathrm{J}$ gene segments during the primary immune response, junctional diversity due to imprecise $\mathrm{V}-(\mathrm{D})-\mathrm{J}$ joining, and later, somatic mutations introduced into the antibody genes during the secondary and tertiary responses as part of the affinity maturation process. Our studies of the immunological evolution of antibody 28B4 and other antibody systems have provided a number of additional insights into these processes. (i) Antigen polyspecificity intrinsic to certain combinations of germline $\mathrm{V}$ genes expands the binding potential of the germline repertoire, while CDR $\mathrm{H} 3$ (encoded by $\mathrm{D}-\mathrm{J}_{\mathrm{H}}$ joining) plays a critical role in defining the ultimate specificity of the antigen-combining site. (ii) The binding of hapten to the germline antibody induces CDR loop conformational rearrangements that result in enhanced complementarity between the antibody and the hapten. The conformational diversity in the germline antibodies also expands the diversity of the primary antibody repertoire. (iii) Mutations introduced into the germline antibody by either $\mathrm{V}-(\mathrm{D})-\mathrm{J}$ joining or somatic hypermutation not only act to decrease CDR loop flexibility and preorganize the hapten binding site but also may induce significant changes in the binding geometry of the hapten for achievement of optimal hapten complementarity. Thus, many weak binding modes may exit in germline antibodies that can be significantly strengthened during affinity maturation. (iv) Somatic mutations can be introduced into the germline antibody at the peripheries of the haptencombining site and affect hapten binding through secondary sphere interactions, or they can occur at the hapten-combining site and affect hapten binding by direct contact. (v) The stepwise acquisition of functional mutations by the germline antibody genes is coupled with stepwise increases in binding affinity between antibody and antigen, which is the common theme observed during in vitro antibody evolution.

\section{REFERENCES}

1. Hsieh-Wilson, L. C., Schultz, P. G., and Stevens, R. C. (1996) Proc. Natl. Acad. Sci. U.S.A. 93, 5363.
2. Wedemayer, G. J., Patten, P. A., Wang, L. H., Schultz, P. G., and Stevens, R. C. (1997) Science 276, 1665.

3. Romesberg, F. E., Spiller, B., Schultz, P. G., and Stevens, R. C. (1998) Science 279, 1929.

4. French, D. L., Laskov, R., and Scharff, M. D. (1989) Science 244, 1152.

5. Mundorff, E. C., Hanson, M. A., Varvak, A. V., Ulrich, H., Schultz, P. G., and Stevens, R. C. (2000) Biochemistry 39, 627.

6. Hsieh, L. C., Stephens, J. C., and Schultz, P. G. (1994) J. Am. Chem. Soc. 116, 2167.

7. Walsh, C., and Latham, J. (1986) J. Protein Chem. 5, 79.

8. Jakoby, W. B., and Ziegler, D. M. (1990) J. Biol. Chem. 265, 20715.

9. Holland, H. L. (1988) Chem. Rev. 88, 473.

10. Ulrich, H. D., Patten, P. A., Yang, P. L., Romesberg, F. E., and Schultz, P. G. (1995) Proc. Natl. Acad. Sci. U.S.A. 92, 11907.

11. Otwinowski, Z., and Minor, W. (1996) Methods Enzymol. 276, 307.

12. Leslie, A. G. W. (1992) Joint CCP4 + ESF-EAMCB Newsletter on Protein Crystallography, No. 26, Cambridge.

13. Navaza, J. (1994) Acta Crystallogr. A50, 157.

14. Jones, T. A., Zou, J.-Y., Cowtan, S. W., and Kjeldgaard, M. (1991) Acta Crystallogr. A47, 110.

15. Brunger, A. T. (1992) Nature 355, 472.

16. Adams, P. D., Pannu, N. S., Read, R. J., and Brunger, A. T. (1997) Proc. Natl. Acad. Sci. U.S.A. 94, 5018.

17. Pannu, N. S., and Read, R. J. (1996) Acta Crytallogr. A52, 659.

18. Kabat, E. A., Wu, T. T., Perry, H. M., Gottesman, K. S., and Foeller, C. (1991) Sequences of Proteins of Immunological Interest, 5th ed., U.S. Department of Health and Human Services, National Institutes of Health, Bethesda, MD.

19. Ulrich, H. D., and Schultz, P. G. (1998) J. Mol. Biol. 275, 95.

20. Ng, K. H., Lavigueur, A., Ricard, L., Boivrette, M., Maclean, S., Cloutier, D., and Gibson, D. M. (1989) J. Immunol. 143 638.

21. Kaartinen, M., Solin, M. L., and Makela, O. (1991) Eur. J. Immunol. 21, 2863.

22. Wilson, P. C., de Bouteiller, O., Liu, Y. J., Potter, K., Banchereau, J., Capra, J. D., and Pascual, V. (1998) J. Exp. Med. 187, 59.

23. Patten, P. A., Gray, N. S., Yang, P. L., Marks, C. B., Wedemayer, G. J., Boniface, J. J., Stevens, R. C., and Schultz, P. G. (1996) Science 271, 1086.

24. Ulrich, H. D., Mundorff, E. C., Santarsiero, B. D., Driggers, E. M., Stevens, R. C., and Schultz, P. G. (1997) Nature 389, 271.

25. Herron, J. N., He, X. M., Ballard, D. W., Blier, P. R., Pace, P. E., Bothwell, A. L., Voss, E. W., and Edmundson, A. B. (1991) Proteins 11, 159.

26. Rini, J. M., Schulze-Gahmen, U., and Wilson, I. A. (1992) Science 255, 959.

27. Wilson, I. A., and Stanfield, R. L. (1993) Curr. Opin. Struct. Biol. 3, 113.

28. Kodandapani, R., Veerapandian, L., Ni, C. Z., Chiou, C. K., Whittal, R. M., Kunicki, T. J., and Ely, K. R. (1998) Biochem. Biophys. Res. Commun. 251, 61.

29. Monaco-Malbet, S., Berthet-Colominas, C., Novelli, A., Battai, N., Piga, N., Cheynet, V., Mallet, F., and Cusack, S. (2000) Struct. Folding Des. 8, 1069.

30. Chothia, C., Lesk, A. M., Tramontano, A., Levitt, M., SmithGill, S. J., Air, G., Sheriff, S., Padlan, E. A., Davies, D., Tulip, W. R., Colman, P. M., Spinelli, S., Alzari, P. M., and Poljak, R. J. (1989) Nature 342, 877.

31. Yang, P. L., and Schultz, P. G. (1999) J. Mol. Biol. 294, 1191.

32. Putterman, C., Deocharan, B., and Diamond, B. (2000) J. Immunol. 164, 2542.

33. Novick, K. E., Fasy, T. M., Losman, M. J., and Monestier, M. (1992) Int. Immunol. 4, 1103.

34. Ichiyoshi, Y., and Casali, P. (1994) J. Exp. Med. 180, 885.

35. Foote, J., and Milstein, C. (1991) Nature 352, 530.

BI010536C 